\title{
A New Reference Plasmid “pGMT27” Provides an Efficient Transgenic Detection Method for Flue-Cured Tobacco
}

\author{
Jing Yu, ${ }^{1}$ Xiaolian Zhang, ${ }^{1}$ Muhammad Faheem Adil $\left(\mathbb{D},{ }^{2}\right.$ Bo Lei, ${ }^{1}$ Mengao Jia, ${ }^{1}$ Huina Zhao, \\ Shizhou Yu, ${ }^{1}$ Jiemin Liu, ${ }^{3}$ Yushuang Guo $\mathbb{D}^{1},{ }^{1}$ and Imran Haider Shamsi $\mathbb{D}^{2}$ \\ ${ }^{1}$ Guizhou Academy of Tobacco Science CNTC, Tobacco Molecular Genetics Key Laboratory of China Tobacco, Guiyang 550081, \\ Guizhou, China \\ ${ }^{2}$ Department of Agronomy, College of Agriculture and Biotechnology, Key Laboratory of Crop Germplasm Resource, \\ Zhejiang University, Hangzhou 310058, China \\ ${ }^{3}$ Guizhou Provincial People's Hospital, Guiyang 550002, Guizhou, China
}

Correspondence should be addressed to Yushuang Guo; yshguo@126.com and Imran Haider Shamsi; drimran@zju.edu.cn

Received 1 August 2021; Revised 1 October 2021; Accepted 19 October 2021; Published 15 November 2021

Academic Editor: Shakeel Ahmed

Copyright $\odot 2021$ Jing Yu et al. This is an open access article distributed under the Creative Commons Attribution License, which permits unrestricted use, distribution, and reproduction in any medium, provided the original work is properly cited.

\begin{abstract}
Owing to the economic value of its foliage, tobacco (Nicotiana tabacum) is cultivated all across the world. For the detection of genetically modified (GM) tobacco, there is a lack of universal standard material which ultimately limits the detection methods because the accuracy and comparability of the results cannot be ensured. Here, we prepared a reference plasmid "pGMT27" for the detection of GM tobacco, which was 18,296 bp in length harboring two of the tobacco endogenous and seven exogenous genes. By using qualitative PCR test for the nine genes, 10 copies were used for plasmid sensitivity. In the quantitative real-time PCR (qPCR) assays with pGMT27 as a calibrator, the reaction efficiencies for $P-35 S$ and $N R$ were $101.427 \%$ and $98.036 \%$, respectively, whereas the limit of detection (LOD) and limit of quantification (LOQ) were 5 copies and 10 copies per reaction. For standard deviation (SD) and relative standard deviation (RSD) of the Ct values, the repeatability values were from 0.04 to 0.42 and from $0.18 \%$ to $1.29 \%$, respectively; and the reproducibility values were from 0.04 to 0.39 and from $0.18 \%$ to $1.14 \%$, respectively. For the unknown sample test, the average conversion factor (Cf) was 0.39 , and the accuracy bias was from $-15.55 \%$ to $1.93 \%$; for precision, the SD values ranged from 0.02 to 0.62 , while RSD values were from $1.34 \%$ to $10.6 \%$. We concluded that using the pGMT27 plasmid as a calibrator provided a highly efficient transgenic detection method for flue-cured tobacco.
\end{abstract}

\section{Introduction}

Tobacco is one of the most widely cultivated nonfood crops and has emerged as an extensively investigated model plant with the accelerated development of molecular biology research. Attributable to its agronomic importance, tobacco is grown in over 125 countries for its foliage, mainly consumed as cigarettes, cigars, and snuff. According to the FAO (Food and Agriculture Organization) data, approximately 4 million hectares of lands are used for cultivating tobacco, one-third of which is in China alone [1]. As smoking is health related [2-4], consumers appear to have more cautious attitudes to tobacco than other crops and GM tobacco, as well as other GM crops. Though applications from biotechnology to tobacco products have been limited, unintentional release of GM tobacco seeds and leaves of nonpermissible sort to the market is possible [5]. Now, GM composition detection in tobacco is becoming an international trade barrier for monitoring the presence of adventitious GM tobacco. So, when entering into the market, it is indispensable for the tobacco companies to enhance controls on import and export of the tobacco product. In many countries, respecting public's right to information and education, the GMO threshold levels of food and feed products have already been established [6-8], Consequently, to ensure the accurate and comparable measurements, selection of standard material for GMO detection becomes critical [9]. The standard reference material includes matrix and plasmid. Plasmid has 
many advantages, such as ease of availability, straightforward manipulation, repeatable production, and low cost [10]. Some plasmids as calibrators have been used for transgenic soybean, maize, cotton, and other crops, including ERM-AD413, ERM-AD415, ERM-AD427, and ERM-AD425. They are also used to calibrate the transgenic maize MON810, NK603, 98140, and transgenic soybean 356043 [11].

However, the lack of standard material has limited the GM tobacco detection methods. Up until now, no standard material as the calibrator for detecting GM tobacco has been found, and no corresponding products have been reported. In the tobacco trade market, tobacco is usually sold in the form of tobacco product, including flue-cured tobacco, redried leaf tobacco, and cigarettes. Here, we reported a plasmid for the GM tobacco test, which was designated as pGMT27. It was constructed based on plant expression vector pBI121. pGMT27 contained two tobacco endogenous genes (actin and NR), genetic elements of the $P$-35S promoter, T-NOS terminators, selective marker genes of NPT II, $H P T, B a r$, and $\operatorname{aadA}$, and GUS reporter gene. These seven exogenous genes could make the screening rate of transgenic tobacco reach $100 \%$ theoretically in our previous screening strategy [12]. Accordingly, a qualitative PCR detection method for detecting the nine targets was developed. Furthermore, a qPCR assay for P-35S and NR was also developed by using plasmid DNA as the calibrator. Thereby, we concluded that using the pGMT27 plasmid as a calibrator provided a highly efficient transgenic detection method for flue-cured tobacco.

\section{Materials and Methods}

2.1. Flue-Cured Tobacco and Genomic DNA Isolation. Transgenic flue-cured tobacco tested by the FAPAS (Food Analysis Performance Assessment Scheme) and CORESTA (Cooperation Centre for Scientific Research Relative to
Tobacco) proficiency test in 2014 was defined as $100 \%$ positive GM with $P$-35S and T-NOS. Nontransgenic fluecured tobacco was collected in our laboratory. All materials were leaves' flour. Plant genome extraction kit (TIANGEN Biotech, China) was employed to extract DNA according to the manufacturer's protocol. Total DNA quantification was performed using a NanoDrop ND-2000 Spectrophotometer (NanoDrop Technologies, USA), OD260/ $\mathrm{OD} 280 \approx 1.80-1.90$, and it was diluted to a $100 \mathrm{ng} / \mu \mathrm{L}$ working stock with sterile distilled water, which was stored at $-80^{\circ} \mathrm{C}$.

2.2. Construction of the pGMT27 Plasmid. According to the screening strategy previously reported [12], we synthesized a 3,818 bp fragment of $H P T+B a r+a a d A+a c t i n+N R$ junction and subcloned it into pMD18-T simple vector by restriction enzyme sites, EcoR I and Sac I. Furthermore, the full-length fragment of five targets was digested with EcoR I/ Sac I and cloned into the plant expression vector pBI121 instead of "T-NOS" with the same enzyme sites, so as to create the recombinant pGMT27 plasmid, which includes nine target DNA fragments consisting of seven exogenous genes and two endogenous. Then, pGMT27 plasmid was isolated and purified by using TIANGEN Plasmid Miniprep Kit (TIANGEN Biotech, China) according to the manufacturer's guidelines. Afterwards, it was identified by Sac II and EcoR I restriction digests and DNA sequencing (Shanghai Generay, China). Total DNA quantification was performed on a Qubit ${ }^{\circledR} 2.0$ Fluorometer (Invitrogen Life Technologies, USA) by using the Qubit ${ }^{\circledR}$ dsDNA BR Assay Kit (Invitrogen Life Technologies, USA) following the manufacturer's directions. The copy numbers were calculated on the basis of pGMT27 plasmid size $(18,296 \mathrm{bp})$ by using Avogadro's constant $\left(6.023 \times 10^{23}\right)$. The plasmid DNA molecular weight $(660 \mathrm{~g} / \mathrm{mol} / \mathrm{dp})$ was calculated with formula (A) proposed by Lee et al. [13].

$$
\text { Formula }(\mathrm{A}): \text { DNA copies }=\frac{6.02 \times 10^{23}(\mathrm{copy} / \mathrm{mol}) \times \mathrm{DNA} \text { amount }(\mathrm{g})}{\text { DNA length }(\mathrm{dp}) \times 660(\mathrm{~g} / \mathrm{mol} / \mathrm{dp})} \text {. }
$$

2.3. Qualitative PCR Assay for the $p G M T 27$ Plasmid. For the LOD test of the qualitative PCR, the plasmid copy number was prepared by $0.1 \times$ TE buffer $(10 \mathrm{mM}$ Tris, $0.1 \mathrm{mM}$ EDTA, and $\mathrm{pH}$ 8.0). All samples were prepared by serially diluting $10^{6}$ copies $/ \mu \mathrm{L}$ to 1 copy $/ \mu \mathrm{L}$, and all the reactions were performed in $20 \mu \mathrm{L}$ volume containing $1.0 \mathrm{U}$ of rTaq DNA polymerase (TAKARA, Japan) and $2 \mu \mathrm{L}$ of $10 \times$ PCR buffer along with $125 \mu \mathrm{M} \mathrm{dNTP}, 0.5 \mu \mathrm{M}$ of primers, and $1 \mu \mathrm{L}$ of plasmid DNA. PCR amplifications were performed in C1000 Touch PCR (Bio-Rad, USA) with the program as follows: one step of $5 \mathrm{~min}$ at $95^{\circ} \mathrm{C} ; 40$ cycles of $30 \mathrm{~s}$ at $94^{\circ} \mathrm{C}, 45 \mathrm{~s}$ at $63-65^{\circ} \mathrm{C}$ (T-NOS annealing temperature was $63^{\circ} \mathrm{C}$, and the others were $65^{\circ} \mathrm{C}$ ), and $45 \mathrm{~s}$ at $72^{\circ} \mathrm{C}$; and $5 \mathrm{~min}$ at $72^{\circ} \mathrm{C}$. Amplification products were electrophoresed in $2 \%$ agarose gels for approximately $40 \mathrm{~min}$ at $100 \mathrm{~V}$. Primers were synthesized and purified by Shanghai Generay Biotech Co., Ltd. (Table S1).

\subsection{Quantitative PCR Assay for the pGMT27 Plasmid}

2.4.1. Reaction System and Conditions. All qPCR amplification reactions were performed in a $20 \mu \mathrm{L}$ final volume containing $10 \mu \mathrm{L}$ of Premix Ex Taq Mix (TAKARA, Japan), $0.5 \mu \mathrm{M}$ of each primer, $0.2 \mu \mathrm{M}$ of probe, $0.4 \mu \mathrm{L}$ of ROX Dye II (50x), and $1 \mu \mathrm{L}$ of plasmid DNA. PCR was in accordance with the following cycling conditions: $95^{\circ} \mathrm{C} 30 \mathrm{~s}, 40$ cycles of $5 \mathrm{~s}$ at $95^{\circ} \mathrm{C}$, and $34 \mathrm{~s}$ at $60^{\circ} \mathrm{C}$. Reactions were run in a ViiA ${ }^{\mathrm{Tm}} 7$ Real-Time PCR System (Invitrogen Life Technologies, USA), and the data were analyzed by ViiA 7 software v1.2. PCR 
primer and probes for $P-35 S$ and $N R$ were synthesized by Shanghai Generay Biotech Co., Ltd. (Table S2).

2.5. Dilution for Standard Curves, Reproducibility, Repeatability, and Sensitivity. To test the availability of pGMT27, the plasmid was prepared as a calibrator and was serially diluted to $10^{6}, 10^{5}, 10^{4}, 10^{3}$, and $10^{2}$ copies $/ \mu \mathrm{L}$ with $0.1 \times \mathrm{TE}$ buffer to construct the standard curves. For the repeatability and reproducibility test, the same five dilution points were also used. Each dilution point was amplified in three replicates. For the reproducibility test, the amplification was finished in three different days. For sensitivity, it included LOD and LOQ, and the pGMT27 plasmid was diluted to 50, 25,10 , and 5 copies $/ \mu \mathrm{L}$ with $0.1 \times \mathrm{TE}$ buffer.
2.6. Conversion Factor (Cf) Calculation and Unknown Samples' Test. In order to minimize the differences between plasmid DNA and plant genomic DNA in PCR efficiencies, calculating the $\mathrm{Cf}$ value is a prerequisite [14]. For the unknown samples' test, $100 \%$ transgenic flue-cured tobacco DNA was diluted into a gradient of $100 \%, 50 \%, 25 \%, 12.5 \%$, and $6.25 \%(\mathrm{~V} / \mathrm{V})$ with the content of $0 \%$ transgenic fluecured tobacco DNA, reactions were run in ViiA ${ }^{T M} 7$ RealTime PCR System, and then target gene and endogenous gene copy number were calculated according to the pGMT27 standard curve. The calculations were performed according to formula (B) suggested by Pi et al. [15], and the final Cf value represented the mean of five calculated Cfs. The unknown sample GM content (\%) was calculated by using formula (C) according to Pi et al. [15]. Each reaction was repeated thrice.

$$
\begin{aligned}
\text { Formula }(B): C f & =\frac{\text { copy number of the exogenous gene }}{\text { copy number of the endogenous gene }}, \\
\text { Formula }(C): \text { GM content }(\%) & =\frac{\text { copy number of the exogenous gene }}{\text { copy number of the endogenous gene } \times \mathrm{Cf}} .
\end{aligned}
$$

\section{Results}

3.1. Construction of the pGMT27 Plasmid and LOD Test by Qualitative PCR. Figure 1 represents a plasmid pGMT27 $(18,296 \mathrm{bp})$, constructed in this study for the qualitative detection of GM tobacco. It harbored nine targets including seven exogenous and two endogenous targets shown in Table 1. Sac II and EcoR I restriction digests (Figure S1) and DNA sequencing (data not given) validated the acquisition of expected plasmids. For testing sensitivity in the qualitative PCR, nine targets by using $10^{6}, 10^{5}, 10^{4}, 10^{3}, 10^{2}, 50,10,5$, and 1 copies of the pGMT27 plasmid as templates were measured by the LOD method. Nine targets were detected as low as 5 copies, which meant that the lowest testing level was 5 copies (Figure 2). However, we recommend that the template should be more than 10 copies if pGMT27 is a positive control plasmid in the practice test work because some groups have no amplification signals in the three repeats when only 5 copies of the templates were present (data not shown); therefore, the uncertainty is obviously greater because of the low template amount.

3.2. Preparation of the pGMT27 Plasmid as the Calibrator. The pGMT27 plasmid was diluted to $10^{6}, 10^{5}, 10^{4}, 10^{3}$, and $10^{2}$ copies $/ \mu \mathrm{L}$, so as to establish standard curves for $P-35 S$ and NR targets for qPCR. Standard curves of the two reactions are displayed in Figure 3. The correlation coefficient $\left(R^{2}\right)$ values of the standard curves were 0.997 and 0.998 for both $P-35 S$ and NR which indicated excellent linearity. PCR efficiencies were $101.427 \%$ and $98.036 \%$, respectively, and data were generated by equation $E=10^{-1 / \text { slope }}-1$ [16] and analyzed by ViiA 7 software v1.2, and standard curves of the two targets showed excellent linearity.
3.3. Repeatability, Reproducibility, LOD, and LOQ for $q P C R$ Assays. For repeatability and reproducibility of Ct from $P$ $35 S$ and $N R$, targets of the pGMT27 plasmid were diluted and amplified for one day and three different days, respectively, and the data are shown and analyzed in Table 2. For the repeatability test, the SD of the Ct values ranged from 0.04 to 0.42 , and the RSD was less than $1.29 \%$. For the reproducibility test, the $\mathrm{SD}$ and $\mathrm{RSD}$ values were in the range of 0.04 to 0.39 and $0.18 \%$ to $1.14 \%$, respectively. For qPCR assays, usually, repeatability of RSD less than $25 \%$ and reproducibility below $35 \%$ were accepted according to the European Network of GMO Laboratories (ENGL) guideline in 2015 [17], and our results indicated good repeatability and reproducibility, which were all in the acceptable range. To test the LOD and LOQ of plasmid pGMT27 in the qPCR, four kinds of concentrations $(50,25,10$, and 5 copies $/ \mu \mathrm{L})$ were prepared. According to ENGL [17], the acceptance criterion of LOD and LOQ should be less than 25 copies and 50 copies, respectively. In the assays, the results determined that the LOD and LOQ were 5 copies and 10 copies per reaction for $P-35 S$ and $N R$, respectively (Table 3 ).

3.4. Estimation of Cf Values and Quantitative Analysis of Unknown Samples. In order to analyze the GM tobacco content of unknown samples by using the pGMT27 plasmid as a calibrator in $\mathrm{qPCR}$, the Cf values were calculated by the copy ratios of $P-35 S$ to $N R$. The endogenous gene $N R$ was a single-copy gene in the tobacco genome [5]. In Table 4, Cf values for each time, including three parallel reactions, were $0.34,0.39,0.40,0.40$, and 0.41 , and the mean value of the Cfs was 0.39 . The SD and RSD values of the Cf were 0.03 and $6.77 \%$, respectively, which were all in the acceptable range. With the aim of testing the GM content of the unknown 


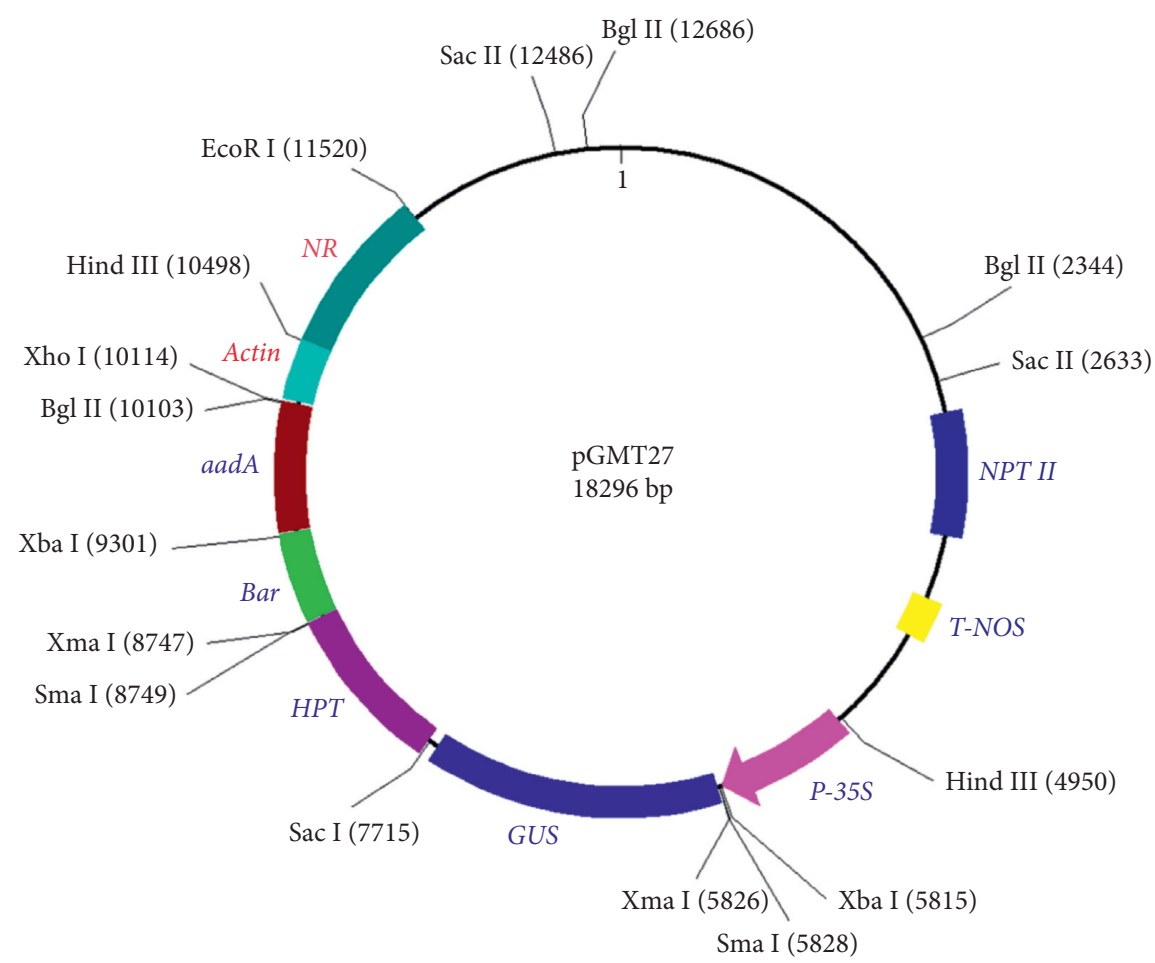

FIGURE 1: Schematic diagram of pGMT27 for the seven GM tobacco events. P-35S, T-NOS, NPT II, GUS, HPT, Bar, and aadA: fragment of the tobacco exogenous gene in red font; actin and $N R$ : fragment of the tobacco endogenous gene in blue font.

TABLE 1: Description of the fragments present in the pGMT27 plasmid (18,296 bp).

\begin{tabular}{|c|c|c|c|c|}
\hline Targets & & Description of genetic elements & $\begin{array}{c}\text { NCBI (accession no. and position of corresponding bp on } \\
\text { the sequence of the accession) }\end{array}$ & $\begin{array}{l}\text { Size } \\
(\mathrm{bp})\end{array}$ \\
\hline \multirow{7}{*}{$\begin{array}{l}\text { Exogenous } \\
\text { genes }\end{array}$} & $P-35 S^{\mathrm{A}}$ & Cauliflower mosaic virus 35 S promoter & AF485783 (4974..5808) & 835 \\
\hline & $\begin{array}{l}N P T \\
I I^{\mathrm{A}}\end{array}$ & Neomycin phosphotransferase II & AF485783 (2838..3632) & 795 \\
\hline & $\begin{array}{c}T- \\
N^{\mathrm{A}}\end{array}$ & $\begin{array}{l}\text { Agrobacterium tumefaciens nopaline } \\
\text { synthase terminator }\end{array}$ & AF485783 (4022..4277) & 256 \\
\hline & $G U S^{\mathrm{A}}$ & Beta-glucuronidase (uidA) gene & AF485783 (5845..7656) & 1,812 \\
\hline & $H P T^{\mathrm{B}}$ & Hygromycin phosphotransferase gene & AF354045 (8948..9973) & 1,026 \\
\hline & $\operatorname{Bar}^{\mathrm{B}}$ & Herbicide-resistant gene & KF840400 (2381..2932) & 552 \\
\hline & $\operatorname{aad} A^{\mathrm{B}}$ & Spectinomycin-resistant gene & EU497669 (3544..4335) & 803 \\
\hline \multirow{2}{*}{$\begin{array}{l}\text { Endogenous } \\
\text { genes }\end{array}$} & $\operatorname{Actin}^{\mathrm{B}}$ & N. tabacum gene for actin & X63603 (4269..4640) & 372 \\
\hline & $N R^{\mathrm{B}}$ & $\begin{array}{l}\text { N. tabacum gene for nitrate reductase } \\
\text { (nia-1) }\end{array}$ & JN384019 (445..1455) & 1,011 \\
\hline
\end{tabular}

A: from plant expression vector pBI121; B: synthesis.

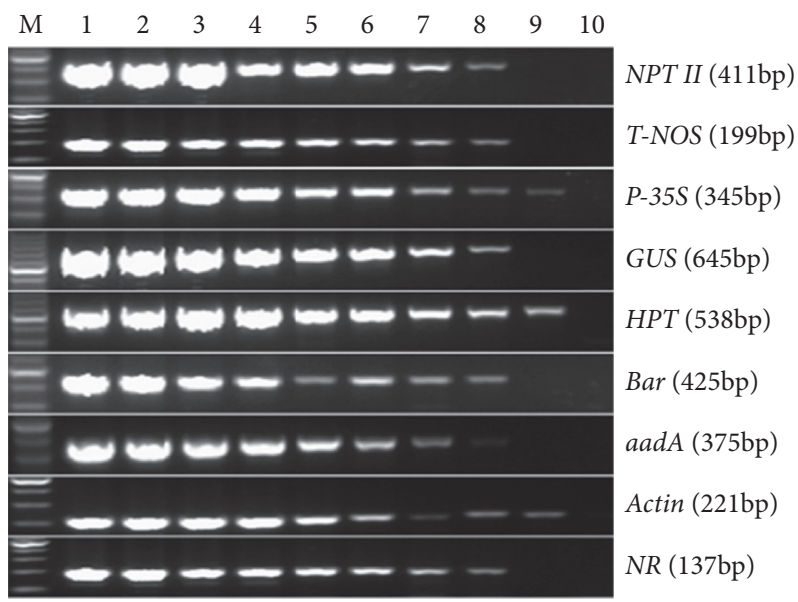

Figure 2: LOD of pGMT27 using qualitative PCR for nine targets. Lane M: TAKARA $100 \mathrm{bp}$ DNA ladder; lanes $1-9: 10^{6}, 10^{5}, 10^{4}, 10^{3}, 10^{2}$, $50,10,5$, and 1 copies/ $\mu$ L; lane 10: NTC. 


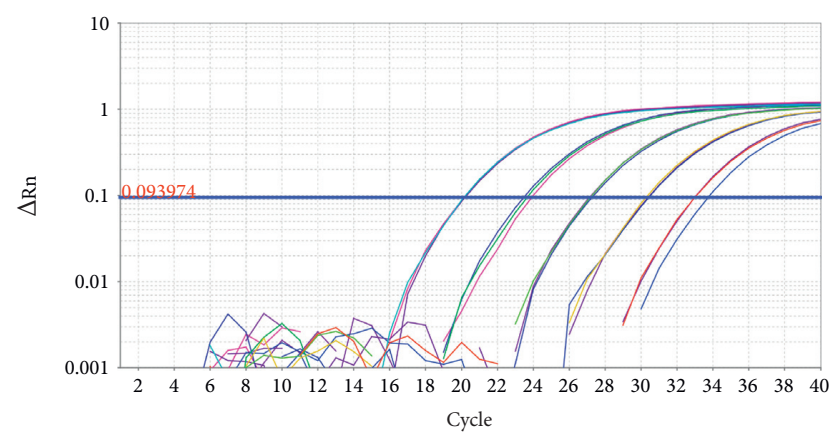

(a)

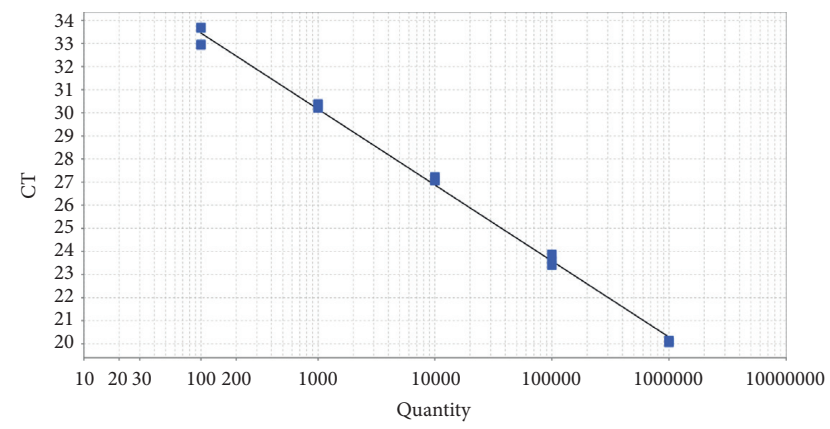

(c)

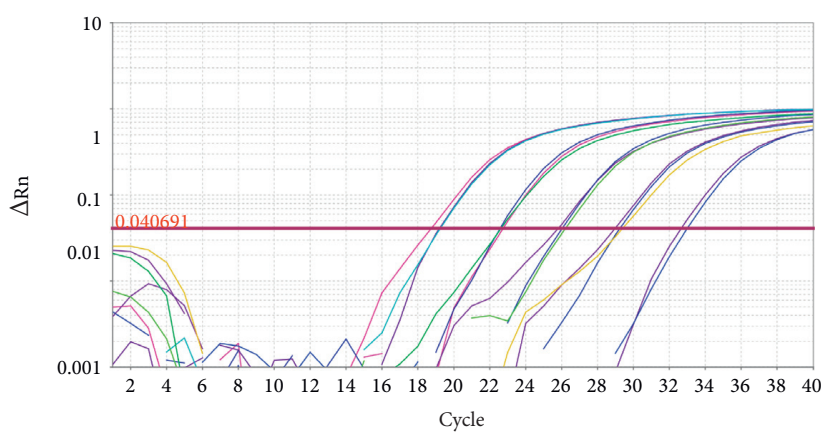

(b)

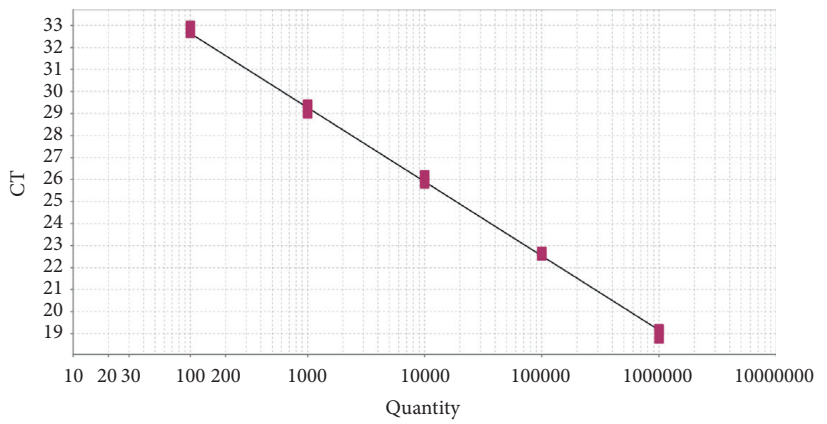

(d)

Figure 3: Calibration curves for $P$ - $35 S$ and NR in qPCR. The dilutions contained approximately $10^{6}, 10^{5}, 10^{4}, 10^{3}$, and $10^{2}$ copies per PCR. (a) Amplification plot of $P$-35S. (b) Amplification plot of NR. (c) Standard curve of $P-35 S\left(y=-3.288 x+40.022, R^{2}=0.997\right.$, Eff\% $\left.=101.427\right)$. (d) Standard curve of $N R\left(y=-3.37 x+39.38, R^{2}=0.998\right.$, Eff\% $\left.=98.036\right)$.

TABLE 2: Repeatability and reproducibility of the pGMT27 plasmid as a calibrator in qPCR.

\begin{tabular}{|c|c|c|c|c|c|c|c|c|c|c|c|c|c|c|}
\hline \multirow[t]{2}{*}{ Targets } & \multirow[t]{2}{*}{ True copy number } & \multicolumn{4}{|c|}{ Ct repeatability (one day) } & \multirow[t]{2}{*}{$\mathrm{SD}$} & \multirow[t]{2}{*}{ RSD (\%) } & \multirow[t]{2}{*}{ True copy number } & \multicolumn{4}{|c|}{$\begin{array}{l}\text { Ct reproducibility } \\
\text { (different days) }\end{array}$} & \multirow[t]{2}{*}{ SD } & \multirow[t]{2}{*}{$\operatorname{RSD}(\%)$} \\
\hline & & 1 & 2 & 3 & Mean & & & & 1 & 2 & 3 & Mean & & \\
\hline \multirow{5}{*}{$P-35 S$} & 100 & 32.96 & 33.68 & 32.94 & 33.19 & 0.42 & 1.28 & 100 & 33.24 & 32.90 & 33.26 & 33.14 & 0.20 & 0.62 \\
\hline & 1,000 & 30.21 & 30.37 & 30.33 & 30.31 & 0.08 & 0.27 & 1,000 & 30.66 & 30.47 & 30.41 & 30.51 & 0.13 & 0.43 \\
\hline & 10,000 & 27.10 & 27.22 & 27.07 & 27.13 & 0.08 & 0.29 & 10,000 & 27.38 & 27.33 & 27.11 & 27.27 & 0.14 & 0.52 \\
\hline & 100,000 & 23.60 & 23.41 & 23.86 & 23.62 & 0.23 & 0.97 & 100,000 & 23.71 & 23.77 & 23.54 & 23.67 & 0.12 & 0.50 \\
\hline & $1,000,000$ & 20.07 & 20.14 & 20.07 & 20.09 & 0.04 & 0.18 & $1,000,000$ & 20.20 & 20.14 & 20.13 & 20.16 & 0.04 & 0.18 \\
\hline \multirow{5}{*}{$N R$} & 100 & 32.16 & 32.99 & 32.65 & 32.60 & 0.42 & 1.29 & 100 & 33.66 & 33.72 & 34.35 & 33.91 & 0.39 & 1.14 \\
\hline & 1,000 & 29.42 & 29.25 & 28.99 & 29.22 & 0.22 & 0.74 & 1,000 & 29.99 & 29.88 & 30.04 & 29.97 & 0.08 & 0.27 \\
\hline & 10,000 & 26.20 & 26.00 & 25.80 & 26.00 & 0.20 & 0.76 & 10,000 & 26.77 & 26.59 & 26.82 & 26.73 & 0.12 & 0.46 \\
\hline & 100,000 & 22.61 & 22.54 & 22.72 & 22.63 & 0.09 & 0.41 & 100,000 & 23.05 & 22.93 & 23.12 & 23.03 & 0.09 & 0.40 \\
\hline & $1,000,000$ & 19.21 & 19.18 & 18.77 & 19.05 & 0.25 & 1.29 & $1,000,000$ & 19.70 & 19.57 & 19.59 & 19.62 & 0.07 & 0.35 \\
\hline
\end{tabular}

samples, six concentrations were used for the analysis, and these samples were $0.5 \%, 2 \%, 5 \%, 6.25 \%, 12.5 \%$, and $25 \%(\mathrm{v} /$ $\mathrm{v})$, which were prepared by mixing the samples of several GM and non-GM flue-cured tobacco DNA. GM percentages of unknown samples were calculated by formula $(\mathrm{C})$. The qPCR analysis is shown in Table 5, where the accuracy of bias ranged from $-15.55 \%$ to $1.93 \%$; however, our bias values were lower than the acceptance criteria (-25\% to $25 \%)$ according to ENGL [17]. Precision of SD and RSD ranged from 0.02 to 0.62 and from $1.34 \%$ to $10.6 \%$. All these results indicated good repeatability, which were all in the acceptable range.

\section{Discussion}

On a global scale, the number of genetically engineered plants has risen exponentially in recent years, adding up to the complexity of efforts taken by the enforcement laboratories to detect not only the authorized GMOs in food and feed samples but also the unauthorized ones. In order to produce reliable data, research laboratories need to harmonize their techniques to quantify GMOs or to demonstrate that different methods used for the quantification of GMOs are commutable [6, 7]. Quantitative examination of GMOs is usually carried out by the determination of the 
TABLE 3: The LOD and LOQ of the pGMT27 plasmid as the calibrator in qPCR.

\begin{tabular}{lcccc}
\hline Target & Template copies & Positive signals/total repeats & Mean Ct & Ct SD \\
\hline \multirow{4}{*}{-35S } & 50 & $9 / 9$ & 34 & 35.08 \\
& 25 & $9 / 9$ & 36.63 & 0.33 \\
& 10 & $9 / 9$ & - & 0.89 \\
NR & 5 & $8 / 9$ & 94.04 & NA \\
& 50 & $9 / 9$ & 35.22 & 0.61 \\
& 25 & $9 / 9$ & 36.03 & 0.38 \\
& 10 & $8 / 9$ & - & 0.76 \\
\hline
\end{tabular}

NA: not applicable.

TABle 4: Conversion factor (Cf) estimation of the reference molecule pGMT27 by qPCR.

\begin{tabular}{lccccc}
\hline \multirow{2}{*}{ Quality of genomic DNA (ng) } & \multicolumn{2}{c}{ Target copies } & Cf & Mean Cf value & SD \\
& $P-35 S$ & 1675.12 & 4905.71 & 0.34 & \\
6.25 & 3850.91 & 9848.56 & 0.39 & 0.39 & 0.03 \\
12.5 & 7782.50 & 19525.56 & 0.40 & 6.77 \\
25 & 15455.08 & 38570.14 & 0.40 & \\
50 & 30893.15 & 76172.85 & 0.41 & & \\
100 & &
\end{tabular}

TABLE 5: Unknown sample analyses for GMO content (\%) using the pGMT27 plasmid as the calibrator $(\mathrm{Cf}=0.39)$.

\begin{tabular}{|c|c|c|c|c|c|c|c|}
\hline \multirow{2}{*}{$\begin{array}{l}\text { True value } \\
(\%)\end{array}$} & \multicolumn{3}{|c|}{$\begin{array}{l}\text { Experimental value } \\
(\%)\end{array}$} & \multicolumn{2}{|c|}{ Accuracy } & \multicolumn{2}{|c|}{ Precision } \\
\hline & 1 & 2 & 3 & $\begin{array}{c}\text { Mean } \\
(\%)\end{array}$ & $\begin{array}{l}\text { Bias } \\
(\%)\end{array}$ & $\mathrm{SD}$ & $\begin{array}{c}\text { RSD } \\
(\%)\end{array}$ \\
\hline 0.5 & 0.40 & 0.39 & 0.47 & 0.42 & -15.55 & 0.04 & 9.84 \\
\hline 2 & 1.71 & 1.75 & 1.75 & 1.73 & -13.29 & 0.02 & 1.34 \\
\hline 5 & 4.26 & 4.28 & 3.90 & 4.15 & -17.08 & 0.21 & 5.16 \\
\hline 6.25 & 6.25 & 5.16 & 5.32 & 5.57 & -10.80 & 0.59 & 10.60 \\
\hline 12.5 & 12.65 & 12.54 & 11.91 & 12.37 & -1.07 & 0.40 & 3.26 \\
\hline 25 & 26.18 & 25.28 & 24.99 & 25.48 & 1.93 & 0.62 & 2.42 \\
\hline
\end{tabular}

Bias $=[($ mean experimental value - true value $) /$ true value $] * 100$.

amount of event-specific target with respect to the reference gene [8]. In the current study, seven exogenous ones were frequent, and the theoretical coverage reached $100 \%$ in the tobacco genetic transformation event [12]. Approaches for the detection and quantification of many event-specific targets of commercially available genetically modified organisms and reference genes are available. Additionally, there are many studies that demonstrate the development of methods and their in-house validation $[6,10]$. Other studies indicated that the LOD was 5 and 20 copies, respectively, by using the plasmid as a reference molecule for detecting transgenic canola and soybean $[18,19]$; correspondingly, in our study, nine targets were detected as low as 5 copies, which meant that the lowest testing level was 5 copies. Nonetheless, it is important to critically evaluate any validation status before implementing a method in the research laboratory for routine sample analyses. For reliable quantification of GMOs, laboratories need appropriate organization and quality management systems, and several critical points should be considered in the analytical procedures, such as sampling, sample preparation, and DNA extraction, which have been described recently [10]. Differential qPCR for the detection of unauthorized GMOs is based on the occurrence of several common elements in different GMOs (e.g., promoter and genes of interest). A statistical model was developed to study the difference between the number of targets of such a common sequence and the number of event-specific targets that can identify the approved GMO and the donor organism of the common sequence. When this difference statistically deviates from zero, the presence of an unauthorized GMO can be deduced [20]. However, this approach has low sensitivity, and it is reliable only if the presence of an unknown GMO exceeds 30\%. Furthermore, a qPCR assay for $P-35 S$ and $N R$ was also developed by using plasmid DNA as the calibrator. The $R^{2}$ values of the standard curves were 0.997 and 0.998 for both $P-35 S$ and $N R$, those $R^{2}$ values $\geq 0.98$ were accepted [9], and other researchers' results ranged from 0.995 to 0.999 [18, 21-23]. Theoretically, the Cf score should be 1.0 for the quantitative PCR test when the exogenous gene and endogenous gene are both one copy $[5,15]$, but in this study, the Cf value was 0.39 , which is far more below 1.0, so we could observe three potential reasons: (1) large differences between plasmid DNA and plant genomic DNA in quantitative PCR efficiencies, and some studies involving crops validate this as $\mathrm{Cf}$ values ranging from 0.53 to 0.83 have been reported [14, 21, 23]; (2) these samples' GM content was defined as $100 \%$ positive by the FAPAS, but the fact was there was less than $100 \%$ GM content; (3) flue-cured tobacco DNA partially degrades after curing [24]. The SD and RSD values of the Cf were 0.03 and $6.77 \%$, respectively, which were all in the acceptable range. The advancement of new approaches that are suitable for the quantitative measurement of specific sequences is a promising solution that can overcome the drawbacks of the currently used ways/methods. In the past, several alternative methods for the detection of GMOs were developed that explored different aspects of amplification, detection, and 
identification approaches $[25,26]$. Recently, additional methods have been developed [27-31]. Consequently, in the current study, a qualitative PCR detection method for detecting the nine targets was developed. Highly linear and efficient reactions indicated that the standard curves of the pGMT27 plasmid were suitable for further quantitative test [32]. Meanwhile, using the pGMT27 plasmid as a calibrator provided a highly efficient method in the transgenic detection of flue-cured tobacco.

\section{Conclusion}

The newly developed screened plasmid pGMT27 provides better coverage of the GM elements that could be present in a sample and will facilitate advancements in the detection of unauthorized/unknown GM tobacco. It includes two tobacco endogenous genes (actin and NR), exogenous gene of the $P$-35S promoter and T-NOS terminators, selective marker genes of NPT II, HPT, Bar, and aadA, and GUS reporter gene. Overall, qualitative and quantitative PCR tests infer that the constructed plasmid is a suitable and costeffective strategy for the detection and quantification of GM tobacco.

\section{Data Availability}

All the data generated or analyzed during this study are included in the main paper and supplementary information files.

\section{Ethical Approval}

Not applicable.

\section{Consent}

Not applicable.

\section{Conflicts of Interest}

The authors declare that there are no conflicts of interest regarding the publication of this paper.

\section{Authors' Contributions}

Jing $\mathrm{Yu}$ conceptualized and investigated the study, provided the methodology, performed formal analysis, and wrote the original draft. Xiaolian Zhang visualized the study and wrote the original draft. Muhammad Faheem Adil edited and reviewed the article. Bo Lei investigated the study and provided formal analysis. Mengao Jia provided the methodology and visualized the study. Huina Zhao contributed to data curation and edited and reviewed the article. Shizhou $\mathrm{Yu}$ visualized the study and performed formal analysis. Jiemin Liu edited and reviewed the article. Yushuang Guo conceptualized the study, contributed to funding acquisition, provided resources, and reviewed and edited the article. Imran Haider Shamsi conceptualized and supervised the study, contributed to funding acquisition, provided resources, and edited and reviewed the article.

\section{Acknowledgments}

This research work was financially supported by the Key Special Program of China National Tobacco Corporation 110202101005 (JY-05), 110202001021 (JY-04), and 110202001030 (JY-13)), Qiankehezhicheng [2018]2344, Department of Science and Technology of Guizhou Province, China (qiankehepingtairencai [2020]6016), National Natural Science Foundation of China (31660510 and 31860491), Sino-Pakistan Project NSFC (Grant no. 31961143008), National Natural Science Foundation of China, International (Regional) Cooperation and Exchange Program, Research Fund for International Young Scientists (Grant no. 31750110462), and Jiangsu Collaborative Innovation Center for Modern Crop Production (JCIC-MCP), China.

\section{Supplementary Materials}

Figure S1: Sac II and EcoR I restriction digests of pGMT27. Table S1: primers used in qualitative PCR. Table S2: primer and probe sequence of $P$ - $35 S$ and NR in qPCR. (Supplementary Materials)

\section{References}

[1] J. Tovar, Tobacco Cultivation in Latin America, Documentos Cede, Santiago, Chile, 2014.

[2] M. Schletzbaum, X. Wang, R. Greenlee, M. E. Piper, and C. M. Bartels, "Predictors of smoking cessation in patients with rheumatoid arthritis in two cohorts: most predictive health care factors," Arthritis Care \& Research, vol. 73, no. 5, pp. 633-639, 2021.

[3] T. Kahraman, A. T. Ozdogar, Z. Abasiyanik, and S. Ozakbas, "Associations between smoking and walking, fatigue, depression, and health-related quality of life in persons with multiple sclerosis," Acta Neurologica Belgica, vol. 121, no. 5, pp. 1199-1206, 2020.

[4] G. A. Meshefedjian, "The smoking spectrum: review of the existing evidence and future directions," Journal of Public Health, vol. 28, no. 1, pp. 105-113, 2019.

[5] G. Bindler, F. Borne, and F. Gadani, Task Force Genetically Modified Tobacco-Detection Methods, CORESTA, Paris, France, 1999.

[6] C. D. Viljoen, B. K. Dajee, and G. M. Botha, "Detection of GMO in food products in South Africa: implications of GMO labeling," African Journal of Biotechnology, vol. 5, pp. 73-82, 2006.

[7] C. Bruetschy, "The EU regulatory framework on genetically modified organisms (GMOs)," Transgenic Research, vol. 28, no. S2, pp. 169-174, 2019.

[8] M. Milavec, D. Dobnik, L. Yang, D. Zhang, K. Gruden, and J. Žel, "GMO quantification: valuable experience and insights for the future," Analytical and Bioanalytical Chemistry, vol. 406, no. 26, pp. 6485-6497, 2014.

[9] M. Caprioara-Buda, W. Meyer, B. Jeynov, P. Corbisier, S. Trapmann, and H. Emons, "Evaluation of plasmid and genomic DNA calibrants used for the quantification of genetically modified organisms," Analytical and Bioanalytical Chemistry, vol. 404, no. 1, pp. 29-42, 2012.

[10] W. Hui, Q. Chong, C. Su, Y. Duan, and H. Bai, "Rapid realtime PCR detection of transgenic crylC rice using plasmid 
molecule as calibrator," European Food Research and Technology, vol. 237, no. 2, pp. 101-107, 2013.

[11] L. Zhang, Y. Wu, G. Wu, Y. Cao, and C. Lu, "Correction of the lack of commutability between plasmid DNA and genomic DNA for quantification of genetically modified organisms using pBSTopas as a model," Analytical and Bioanalytical Chemistry, vol. 406, no. 25, pp. 6385-6397, 2014.

[12] J. Yu, X. Zhang, D. Zhao, J. Zhou, and J. Zhao, "Screening strategy of genetic elements used in transgenic study," Acta Tabacaria Sinica, vol. 20, no. 1, pp. 81-86, 2014.

[13] C. Lee, J. Kim, S. G. Shin, and S. Hwang, "Absolute and relative QPCR quantification of plasmid copy number in Escherichia coli," Journal of Biotechnology, vol. 123, no. 3, pp. 273-280, 2006.

[14] R. V. Ballari, A. Martin, and L. R. Gowda, "A calibrator plasmid for quantitative analysis of insect resistant maize (Yieldgard Mon 810)," Food Chemistry, vol. 140, no. 1-2, pp. 382-389, 2013.

[15] L. Pi, X. Li, Y. Cao, C. Wang, L. Pan, and L. Yang, "Development and application of a multi-targeting reference plasmid as calibrator for analysis of five genetically modified soybean events," Analytical and Bioanalytical Chemistry, vol. 407, no. 10, pp. 2877-2886, 2015.

[16] F. Wang, X. Zhang, J. Feng, Z. Wang, and P. Wang, "Establishment of a quadruplex real-time PCR for screening of genetically modified tomatoes," European Food Research and Technology, vol. 238, no. 4, pp. 683-690, 2014.

[17] European Network of GMO Laboratories (ENGL). Definition of Minimum Performance Requirements for Analytical Methods of GMO Testing. (2015). https://www.researchgate. net/publication/277939211.

[18] Y. Qiu, M. Zhang, Y. Yu, A. Wang, and X. Gao, "The construction of pMD18-HT-Soybean as a calibrator plasmid and nested PCR assay for herbicide-tolerant soybeans," European Food Research and Technology, vol. 238, no. 3, pp. 375-386, 2014.

[19] M. Chaouachi, A. B. Hafsa, N. Nabi, M. S. Zellama, and K. Said, "A new dual plasmid calibrator for the quantification of the construct specific GM canola Oxy-235 with duplex realtime PCR," Food Chemistry, vol. 145, no. 145C, pp. 49-56, 2014.

[20] K. Cankar, V. Chauvensy-Ancel, M.-N. Fortabat et al., "Detection of nonauthorized genetically modified organisms using differential quantitative polymerase chain reaction: application to 35 S in maize," Analytical Biochemistry, vol. 376, no. 2, pp. 189-199, 2008.

[21] A. Toyota, H. Akiyama, M. Sugimura et al., "Quantification of genetically modified soybeans using a combination of a capillary-type real-time PCR system and a plasmid reference standard," Bioscience, Biotechnology, and Biochemistry, vol. 70, no. 4, pp. 821-827, 2006.

[22] X. Wang, D. Teng, Y. Yang, F. Tian, Q. Guan, and J. Wang, "Construction of a reference plasmid molecule containing eight targets for the detection of genetically modified crops," Applied Microbiology and Biotechnology, vol. 90, no. 2, pp. 721-731, 2011.

[23] X. Wang, D. Teng, D. Xi, Q. Guan, and J. Wang, "Construction of a reference plasmid containing ten targets for the detection of genetically modified crops," Plasmid, vol. 69, no. 1, pp. 108-113, 2013.

[24] M. A. Lin, G. C. Wang, Z. B. Luo, X. T. Kou, and W. L. Zhang, "The optimization of conditions for the extraction of genomic DNA in flue-cured tobacco," Journal of Zhengzhou University of Light Industry, vol. 28, no. 2, pp. 59-63, 2013.
[25] A. Holst-Jensen, "Testing for genetically modified organisms (GMOs): past, present and future perspectives," Biotechnology Advances, vol. 27, no. 6, pp. 1071-1082, 2009.

[26] J. Zel, M. Milavec, D. Morisset, D. Plan, G. Van den Eede, and K. Gruden, How to Reliably Test for GMOs, Springer, New York, NY, USA, 2012.

[27] F. C. A. Brod, A. Z. Dinon, D. J. Kolling, J. C. Faria, and A. C. M. Arisi, "Development of plasmid DNA reference material for the quantification of genetically modified common bean embrapa 5.1," Journal of Agricultural and Food Chemistry, vol. 61, no. 20, pp. 4921-4926, 2013.

[28] J. Guo, L. Yang, L. Chen et al., "MPIC: a high-throughput analytical method for multiple DNA targets," Analytical Chemistry, vol. 83, no. 5, pp. 1579-1586, 2011.

[29] J. Guo, L. Chen, X. Liu et al., "A multiplex degenerate PCR analytical approach targeting to eight genes for screening GMOs," Food Chemistry, vol. 132, no. 3, pp. 1566-1573, 2012.

[30] J.-H. Kim, D. Zhang, and H.-Y. Kim, "Detection of sixteen genetically modified maize events in processed foods using four event-specific pentaplex PCR systems," Food Control, vol. 35, no. 1, pp. 345-353, 2014.

[31] N. Shao, S.-M. Jiang, M. Zhang et al., "MACRO: a combined microchip-PCR and microarray system for high-throughput monitoring of genetically modified organisms," Analytical Chemistry, vol. 86, no. 2, pp. 1269-1276, 2014.

[32] W. Meyer, M. Caprioara-Buda, B. Jeynov, P. Corbisier, S. Trapmann, and H. Emons, "The impact of analytical quality criteria and data evaluation on the quantification of genetically modified organisms," European Food Research and Technology, vol. 235, no. 4, pp. 597-610, 2012. 